\title{
A Unique Control Strategy and Power Management in Wind/Solar Renewable Energy Power System to Improve the Power Quality of Grid System
}

\author{
Khashiya Parveen \\ M. Tech Scholar \\ Energy Technology \\ Truba Institute of Information and Technology \\ Bhopal, M.P, India \\ erkhashiyaparveen16@gmail.com
}

\author{
Prof. Shravan Vishwakarma \\ Assistant professor \\ Energy Technology \\ Truba Institute of Information and Technology \\ Bhopal , M.P, India \\ shravanmits@gmail.com
}

\begin{abstract}
Hybrid energy generation which includes both wind and solar energy has grown exponentially in latest years, and this will continue. Power quality problems such as voltageswells, voltage-sags, harmonic components, power factor, and inadequate voltage control are caused by intermittent various exposures and the incorporation of wind-turbine and Photovoltaic power generating systems with the grid. A Static Compensator (STATCOM) is employed to enhance powerquality. The power quality enhancement method for gridconnected wind-turbine and photo voltaic power plants employing STATCOM is introduced in this paper. The framework of the proposed methodology describes in order to improve the transient voltage stability of the large-scale wind / solar hybrid system, the STATCOM reactive power compensation device is connected to the grid. The compensator is offered to further improve output parameters such as voltage THD, current THD and active power.
\end{abstract}

Keywords: STATCOM, Compensators, Power Quality, Hybrid Renewable Energy (RES), Power Generators.

\section{INTRODUCTION}

Power market has grown in latest decades as a result of population development of industry. As an outcome, power generation may pose serious problems. Renewable and nonrenewable energy sources can be used to produce electricity. As a result of the continued use of nonrenewable resources for the electricity produced, rising temperatures, environmental damage, and the reducing supply of fossil fuels, their price is rising. As a result, renewable energy sources (RES) must be considered as a long term energy solution. Across all renewable energy sources for electricity generation, the wind energy generation and solar energy generation system is the most less expensive and efficient.

The term "Power-Quality" has become increasingly appropriate in the case of power-electronic devices in past few years. Whereas the engineers are often enthusiastic about this subject, it sparked a lot of interest in the nineties since power production efficiency seems strange to all. Sequenced and non-sequenced waves representations are the two sorts of waves representations that relate to power-quality.

Sequenced representations are the ideas that occur at the same time as such AC waveforms at the frequencies of the signals. The phrase "power generation quality" tends to mean variety of meanings. Whereas other power production engineers agree that the word refers to a relevant highest extent of electrical supply, no universally accepted definition exists beyond that. The prerequisites of the machines becoming offered the interpretation of power quality. Whatever is improved energy performance for an electric engine for a windows pc may not be good enough. The term "power quality" refers to the ability of a sine waves to maintain its stages of voltages at the rated voltage $\&$ frequency. The wave function of electrical power is truly sinusoidal and undistorted during the introductory stage.

Furthermore, rising fuel costs make them impractically expensive to implement. Additionally, they substantially pollute the air. Renewables such as solar energy and wind power are available in several of these distant regions and can provide fresh, less-expensive power. All power electrical / electronic gadgets suffer from power quality (PQ) issues once connected to a distribution grid. As a result, current (I) and voltage (V) disturbances occur, resulting in low equipment efficiency and energy breakdowns.Expansion of usage of electronic circuits in the grid as well as commercial sector take place rapidly, distributors must concentrate on selecting a device. The Distribution Compensator is valuable and powerful gadget for acknowledging power quality issues among all controllers.

Scholars and practitioners are becoming increasingly concerned with generating power from renewable energy sources (RES), resulting in more consistent electrical power allotment processes that address power-quality conflicts. In 
such scenario, both electricity usage and increasing consumer awareness regarding power quality. The majority of methodologies are created by programmers in order to meet the needs of users. Consumers may occasionally require a higher level of quality than that provided by designed energy infrastructure systems.

\section{LiterATURE REVIEW}

AK. Mischra et al. [1]This paper describes a hybrid active power shunt filter (HSAPF) that was evaluated using a combination of grey wolf particle swarm optimization (PSOGWO) and a proportional-integral-differential control system. Harmonic compensation in both stable and unstable load situations. To reduce harmonics, the FOPID control system variables are initialized utilizing PSO-GWO new technique. By contrasting passive and active filtration systems, it can be determined that the former are large in size and challenging in architecture, while the latter are not suitable for a high rating. A So that, employing MATLAB / Simulink and an actual test configuration, an active-passive hybrid shunt filtration system framework is established. The active bypass filtration system compensation method varies from observable techniques like as $(p-q)$ or I d - I q) concept, which only require the detection of the sourcecurrent. The presented controller's performance is assessed in a wide range of scenarios, including consistent and transitory states, and variables like distortion in harmonic components, feeding power factor (IPF), efficacious power $(\mathrm{P})$, and reactive power $(\mathrm{Q})$ are determined and compared to certain other control systems.PSO, GWO, and hybrid PSOGWO methodologies are used to optimize the variables of the FOPIDC and traditional PID control system. In different operational conditions, FOPIDC depending HSAPF optimized for PSO-GWO outperforms HSAPF relying PSO / GWO optimized and CPIDC relying HSAPF, according to computation and scientific study outcome.

J.Ma et al. [2]By attempting to control the BESS, this article proposes a highly inefficient decentralized controlling approach for maintaining market driven stability. When only the flow of information among nodes in the network is actually needed, the computing and management load is delegated to the regional controllers, avoiding the cost and complexity of a centralized control system. A rigid analysis proves the consistency of the suggested control scheme. The proposed network control and the centralizedoptimized control strategies are compared, and the numerical simulations illustrate the effectiveness of the suggested solution.

W.U. Tareen et al. [3] This research was conducted to determine the high tech Active Power Filters by limiting the quantity of electrical devices as well as the expense, dimensions, and mass of grid-connected inverters. Numerous investigations takes place for conceptual study as well as experimentally comparison were done on low-operation Active Power Filters inverter structures in single-phase and three-phase systems, including AC to AC, Back to Back, and Common-Leg. Current research is focused on cost-effective methods to alleviate the quantity of elements, inverters which do not involve transformers, and Active Power Filters that relies on multiphase and multipurpose inverters in solar and wind energy conversion systems.Recent methodologies for implementing innovative inverter depending equipment for renewable energy resources, as well as their constrictions, are explored with stated reasons. As a result of this overview, industrial researchers may be able to enhance energy-quality in Photovoltaic system and WEA power transmission and distribution network services.

NB Kumar et al. [4] The circuit model of a dual voltage source inverter (DVSI) is provided in this paper to achieve better power quality as well as stability of the micro-grid system. The suggested technique involves two inverters that enable the micro-grid to share energy produced by renewable energy sources (RES) while also compensating for the unstable and fluctuated load in the area. The control techniques for continuing to operate the DVSI in the system sharing and network injectors operation conditions are depending on the notion of momentary symmetric components (ISCT).Highly stable, reduced bandwidth prerequisites of the primary inverter, reduced prices due to a compact filter dimensions, and optimum management of the microgrid's power are all advantages of the suggested technique, which uses a poor rated voltage for the primary inverter. Because of these characteristics, the DVSI framework is an effective alternative for micro-grids with load variations. Wide - ranging simulation results and experimental data are used to authenticate the controlling configuration and algorithm.

N.R. Tummuru et al. [5]U Employing the automatic symmetric element concept, this paper suggests a control scheme for the micro-grid side voltage source converter (GVSC). The G-Voltages Source Controller with the presented approach can be employed as a bi-directional energy communicating converter to control power circulation from the Dc grid to the Ac grid and conversely, relying on RES existed in the DC link; and 2) as an energy quality compensator including reactive power compensation, load balancing, and energy absorption of harmonic current produced by fluctuating loads in the common interconnecting point, by which system can deliver a sine wave curve.3) Employing a damping filtration system in the control method, efficiently and successfully dampen the vibrations of the (meu)G Voltage Source Controller currents. The frequency domain methodology is used to derive 
computational equations and analyses the stabilization different facets in depth. Extended simulations are used to illustrate the suggested control algorithm's multi-operational characteristics, that are also substantiated by test findings.

Y. Zhang et al. [6]Owing to low communication strategy and ruggedness against bankruptcy cases, distributed power system is of foremost relevance in smart grids, particularly micro-grids with distributed generation (DG) as well as distributed storage (DS), as reported in this paper. The distributed financial allotment for a microgrid with rising renewables insertion and order fulfillment in on-grid configuration is investigated in this manuscript. A novel method to power generation is proposed to address the intrinsically stochastic accessibility of renewable energy sources (RES).In order to secure market driven stability, the framework involves both real renewable energy and energy swapped with the mains supply. The traditional scheduling approach minimizes the microgrid's cost savings, along with DG and DS expenses, the rewards of allocable loads, with worst processing fees due to renewable energy sources' unpredictability. The constructed optimal solution in a distributed manner by the control centers of the DG, DS, and dispatchable loads utilising a dual dissolution. The efficiency of the novel strategy is confirmed by calculated model.

\section{METHODOLOGY}

A booster station connects the huge hybrid wind and solar system to the grid. A wind turbine and a photo - voltaic system make up the equipment. The Stationary Compensator reactive power compensation machine is linked up with the grid to strengthen the transitory voltage-stability of the huge wind / solar hybrid model. The compensator is available to boost various variables like voltage Harmonic distortion, current THD, and active power. The horizontal axis model (HAWT) and the vertical axis model (VAM) are the two major categories of wind turbines (VAWT). Throughout most wind industry segments, HAWTs are recommended over VAWTs owing to its high effectiveness. VAWTs have the benefit of employing wind energy from all orientations, due to their relatively low effectiveness than HAWTs. Furthermore, because its cutting force is poor, it can produce power even when wind-speeds are limited. VAWTs are most useful for smaller implementations like roofs.

There seems to be a surge in aim of developing tidal wind resources in current history. As a result, horizontal axis floating wind-turbines (FHAWT) and vertical axis wind turbines (FVAWT) are now more commercially viable. A wind power plant typically includes a number of features and sub-assemblies, including the generation system, rotor hub and blades, gear-box, and tower.The wind-turbine's aerodynamic production power is measured as:

$$
P_{\text {Turbine }}=\frac{1}{2} \rho A C_{p}(\lambda, \beta) v^{3}(1)
$$

The air density $\rho$ (usually $1.225 \mathrm{~kg} / \mathrm{m} 3$ ), $\mathrm{A}$ is the area pushed by the rotor blades (in $\mathrm{m} 2$ ), $\mathrm{CP}$ is the coefficient of power converters, and $\mathrm{v}$ is the wind speed (in $\mathrm{m} / \mathrm{s}$ ) are all used in this equation.

The tip-speed ratio is calculated as follows:

$$
\lambda=\frac{\omega_{m} R}{v}(2)
$$

The wind turbine mechanical torque outcome Tm is shown as

$$
T_{m}=\frac{1}{2} \rho A C_{p}(\lambda, \beta) v^{3} \frac{1}{\omega_{m}}
$$

The power coefficient is a fluctuating function of the tipspeed ratio $\lambda$ and the blade pitch angle $\beta$ (in degrees).

Then Power output is given by

$$
P_{\text {Turbine }}=\frac{1}{2} \rho A C_{p_{\text {max }}} v^{3}
$$

A generic equation is used to model the power coefficient CPbased on the modeling turbine features.

$$
C_{p}=\frac{1}{2}\left(\frac{116}{\lambda_{i}}-0.4 \beta-5\right) e^{-\left(\frac{21}{\lambda_{i}}\right)}
$$

MPPT is a feature of the wind originator power characteristic in which the output power is raised with increasing speed of the wind. The turbine rotor performs at a fluctuating speed as a result of the WECS load regulation, continuously retrieving highest energy from the wind.

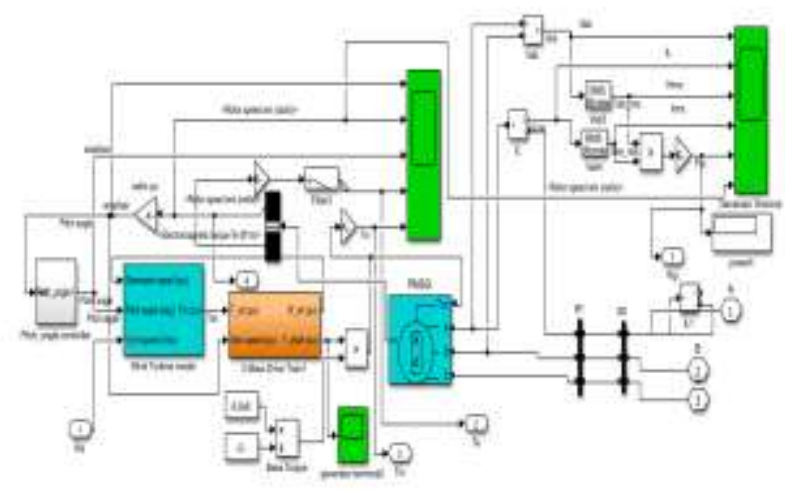

Figure 1Designed Wind Generator System

Table 1:Wind energy system parameters

\begin{tabular}{|c|c|}
\hline Base Wind speed & $12 \mathrm{~m} / \mathrm{sec}$ \\
\hline Type of machine & Permanent Magnet \\
& Synchronous Machine \\
\hline
\end{tabular}




\begin{tabular}{|c|c|l|c|}
\hline Nominal power & $9 \mathrm{MW}$ & Quantity series modules & 25 \\
\hline Frequency & $50 \mathrm{hertz}$ & Open circuitry voltage & 36.3 Volts \\
\hline Stator phase resistance & $0.475 \mathrm{ohms}$ & Shot circuitry current & 7.84 Ampere \\
\hline Flux Linkage & 0.433 & \multicolumn{2}{|}{} \\
\hline Armature inductance & $0.000395 \mathrm{H}$ & \multirow{2}{*}{ The } &
\end{tabular}

The STATCOM depending on a cascade H-bridge, which

Photovoltaic cells have a individual operating position at which the cell's current (I) and voltage (V) yield the highest electrical output. These numbers correlate to a resistance that is equal to V / I. A simplified PV cell circuit model is shown.

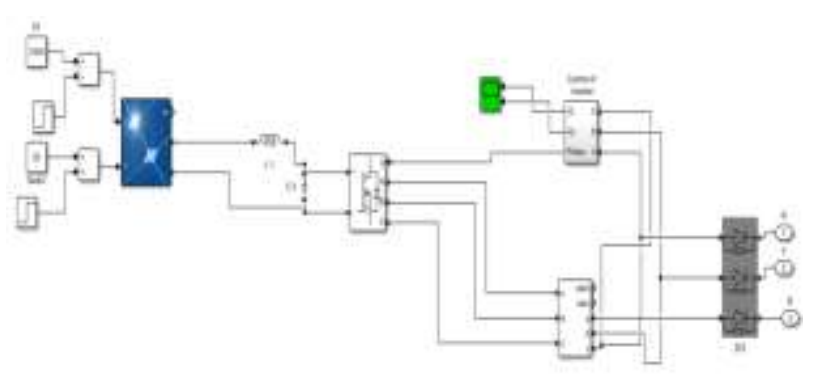

Figure 2Designed Solar Energy System

A parallel pairing of cell-photocurrent,exponential diode (D), and shunt resistance (Rsh) is connected in series with a cell series resistance (Rs), where I pv and $\mathrm{Vpv}$ are the cells current and voltage, respectively. It can be stated as follows:

$I_{p v}=I_{p h}-I_{s}\left(e^{\frac{q\left(V_{p v}+I_{p v} * R_{s}\right)}{n K T}}-1\right)-\frac{V_{p v}+I_{p v} * R_{s}}{R_{s h}}$

A PV cell has an exponential relationship between current and voltage and the maximum power point (MPP) occur at the knee of the curve

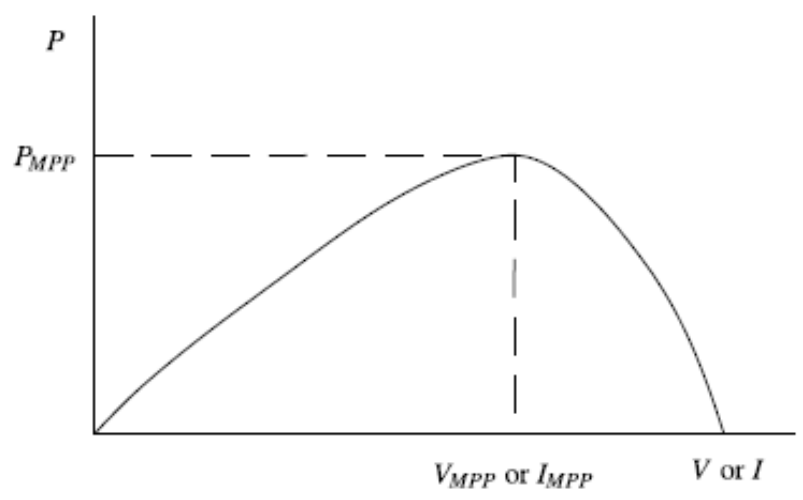

Figure 3Curve of Photovoltaic Array

\begin{tabular}{|l|c|}
\hline \multicolumn{2}{|c|}{ Table 2: PV module Variables per cell } \\
\hline Highest Power per cell & 213.5 Watts \\
\hline Quantity of parallel strings & 100 \\
\hline
\end{tabular}
can interact both in delta and star modes. When using hopped waveform modulation, a conventional multistage cascade $\mathrm{H}$ bridge converter includes a large quantity of H-bridge cells to attain reduced current deformation.

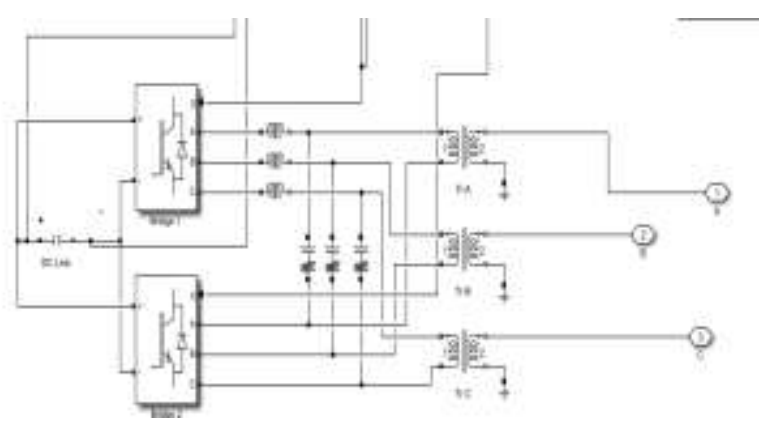

Figure 4 Dual Converter STATCOM Configuration

A control system that is relied on voltage regulation. This strategy is a natural development from traditional bipolar and unipolar Pulse width modulation. For MLI with three arm bridge cells, this modulating scheme is among the most frequently used modulating techniques.

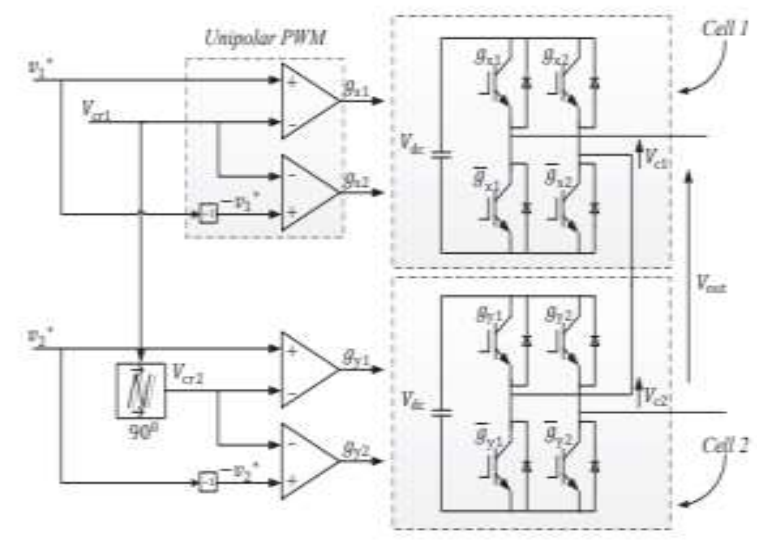

Figure 5Single Phase STATCOM's PWM Technique for Unipolar PWM

The having switched trend and thus the active power are distributed evenly between all cells because the modulating signals and carrier frequency are the same across all cells. The benefit of even power systems is that, inside the scenario of BRIDGE-STATCOM, once a DC-link capacitors are appropriately charged, no disbalance in the DC-link voltages is generated. Furthermore, the overall output wave function has a swapping trend that is $\mathrm{n}$ instances the swapping trend of every cell allows for effective phase shift angle shortlisting among carriers. 


\section{RESULTS \& DISCUSSIONS}

In an entire planet within which energy resources are now becoming rare and expensive, it is critical to use a renewable energy source to achieve future requirements. To counteract the consumption of depleted resources, the best option is to produce electricity using wind and solar power assets. The greatest feature is that it is a smooth power source. For our work on these resources, we've decided to use this domain.

The solar-photovoltaic hybrid model, with whom the DC output power is supplied to the inverter and transformed to a three-phase Ac signal, is the objective of the study. Before ever being supplied into the distribution system and functioning the large weight, the compensator is often used.. The goal of our research is to improve THD and system output, resulting in better and more consistent output values.

Case 1: A renewable energy hybrid approach with STATCOM controlled by base voltage regulation drives heavy loads.

Case 2: A renewable energy hybrid framework is used to control heavy loads, with compensation managed by the PQ PI controller.

Photovoltaic panels with 10 cells within every row and 40 parallel sections were used to design the solar panel, that together provide us the system's DC output.

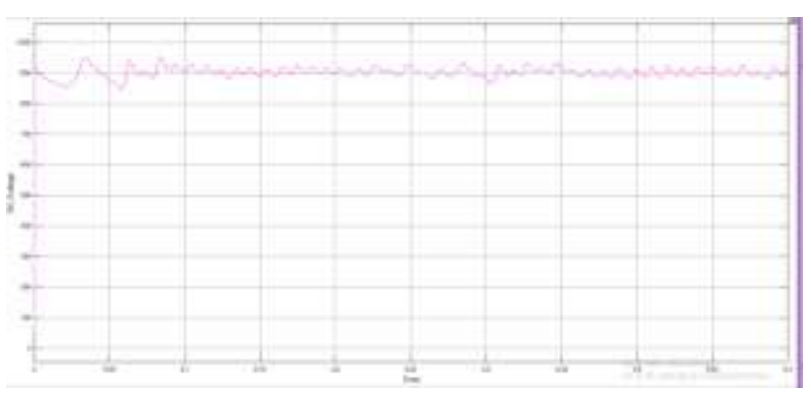

Figure 6 DC output voltage from the hybrid solar wind energy system in SIMULINK

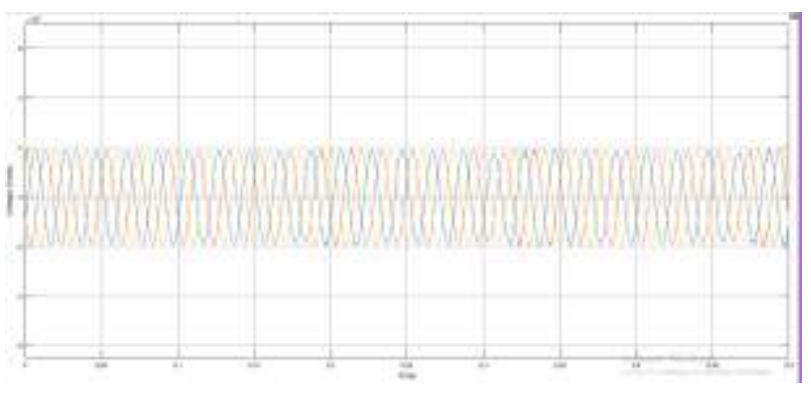

Figure 7Voltage available at the bus $\mathrm{B} 1$ before compensation

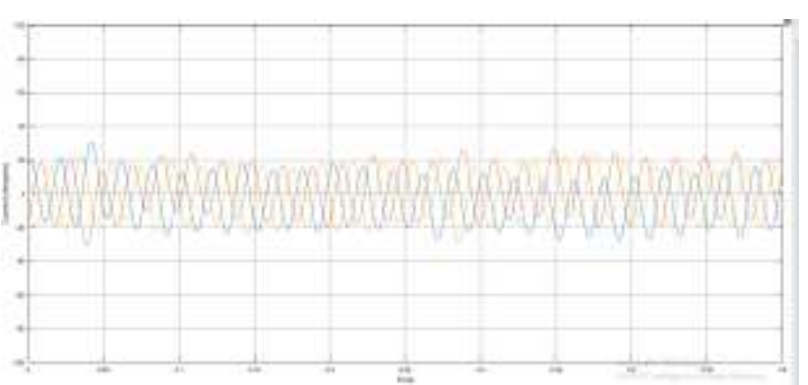

Figure 8Current available at the bus B1 before compensation

Case 1: Hybrid renewable energy model driving heavy loads with STATCOM controlled by basic voltage regulation control.

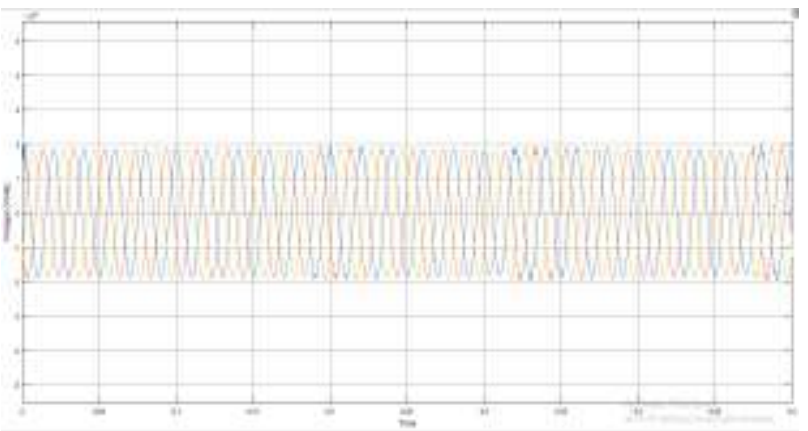

Figure 9AC Voltage available at the loading point in system having voltage regulation control for compensation

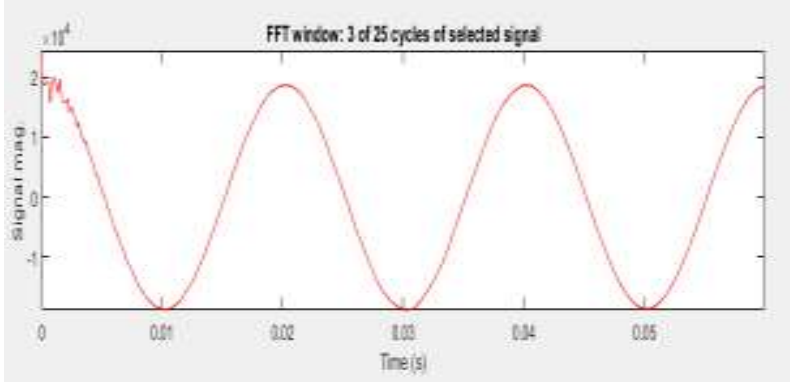

Figure 10 FFT analysis of Voltage in system having voltage regulation control for compensation

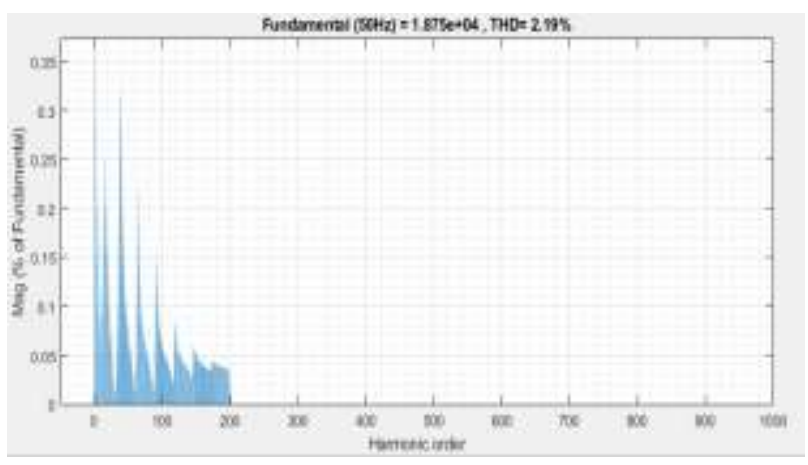

Figure 11 THD \% of Voltage in system having voltage regulation control for compensation 


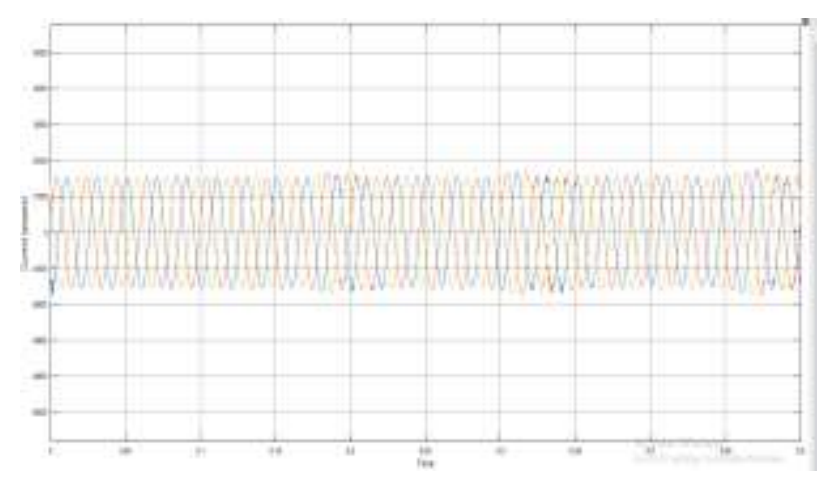

Figure 12 Current driven at the loading point in system having voltage regulation control for compensation

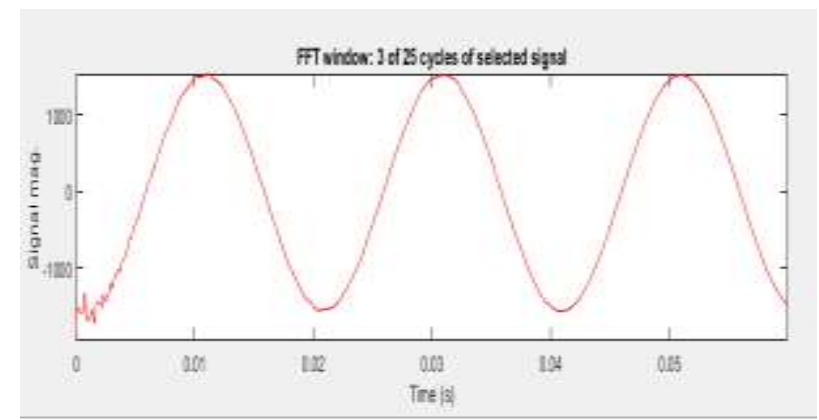

Figure 13 FFT window of Current driven at the loading point in system having voltage regulation control for compensation

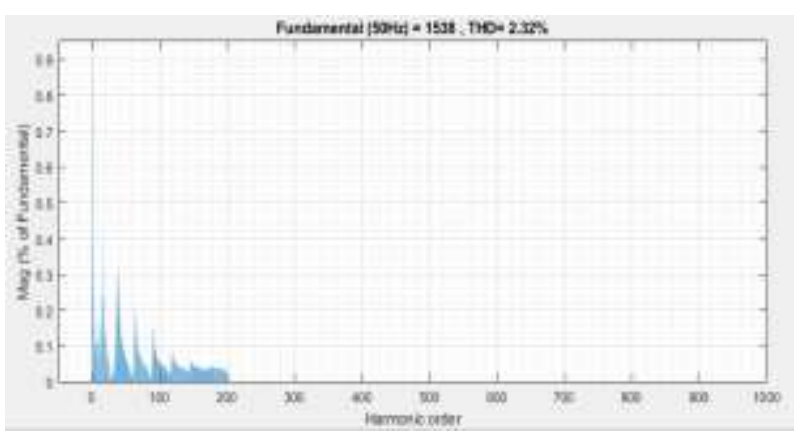

Figure 14 THD\% of Current driven at the loading point in system having voltage regulation control for compensation

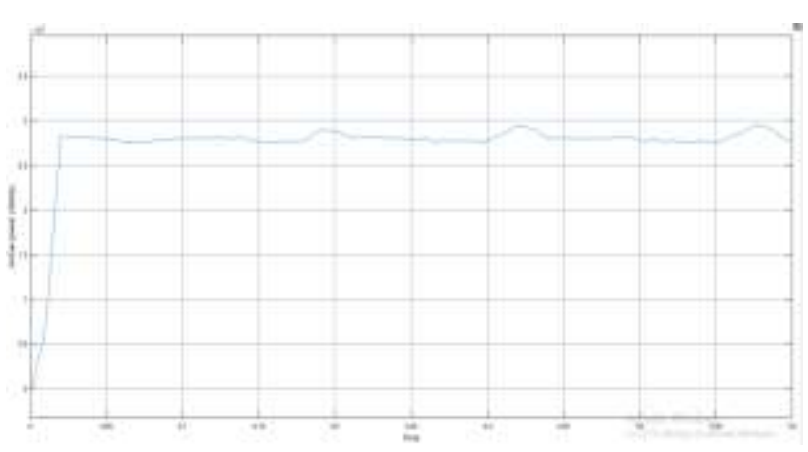

Figure 15 Active Power at the loading point in system having voltage regulation control for compensation

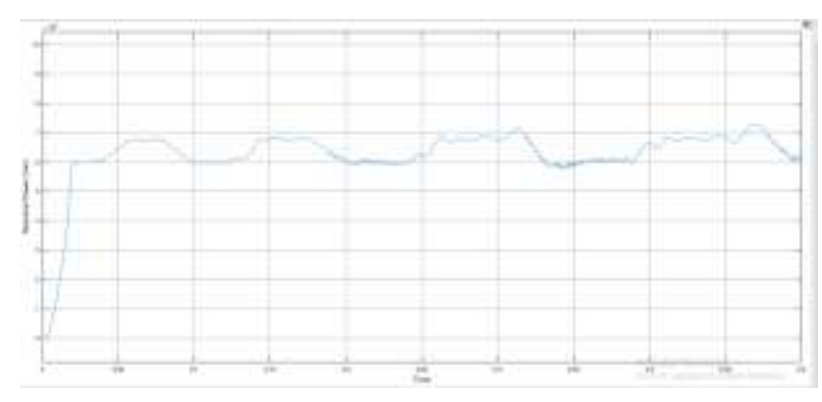

Figure 16 Reactive Power at the line in system having voltage regulation control for compensation

Case 2: Hybrid renewable energy model driving heavy loads with compensation controlled by PQ_PI controller

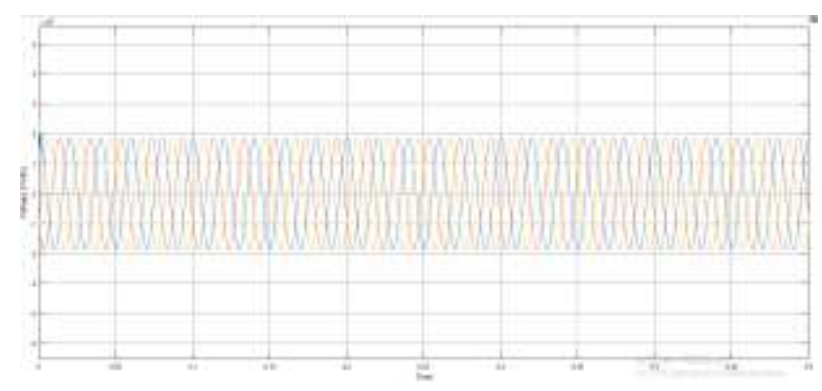

Figure 17 AC voltage available at the loading point in system having PQ_PI controller for compensation

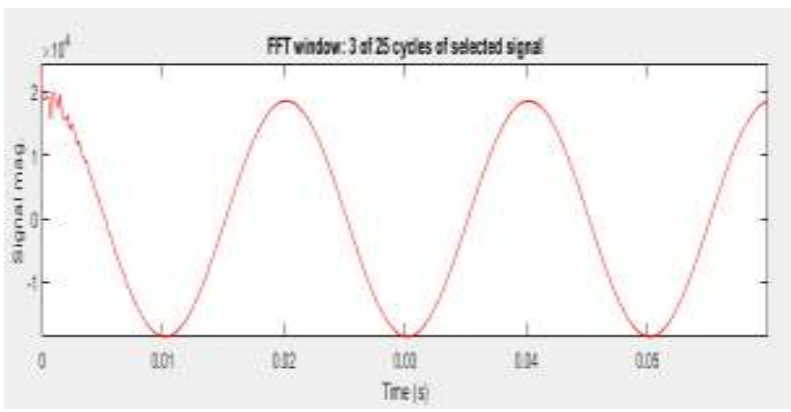

Figure 18FFT of the AC voltage at the loading point in system having PQ_PI controller for compensation

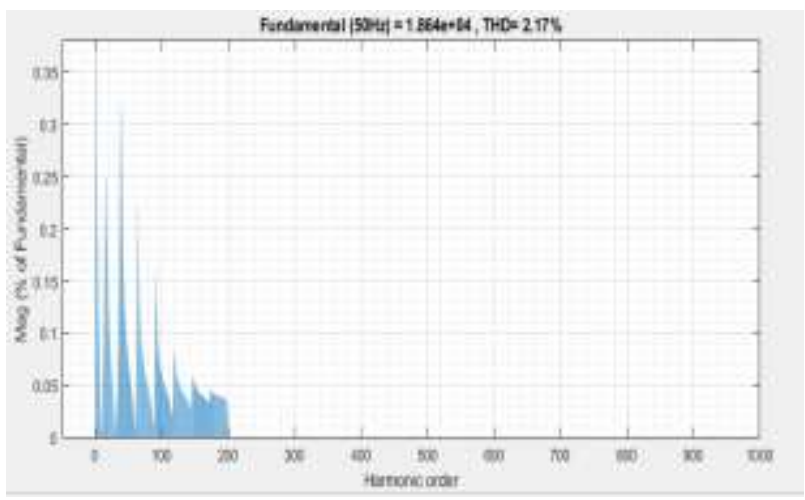

Figure 19 THD \% of AC voltage at the loading point in system having PQ_PI controller for compensation 


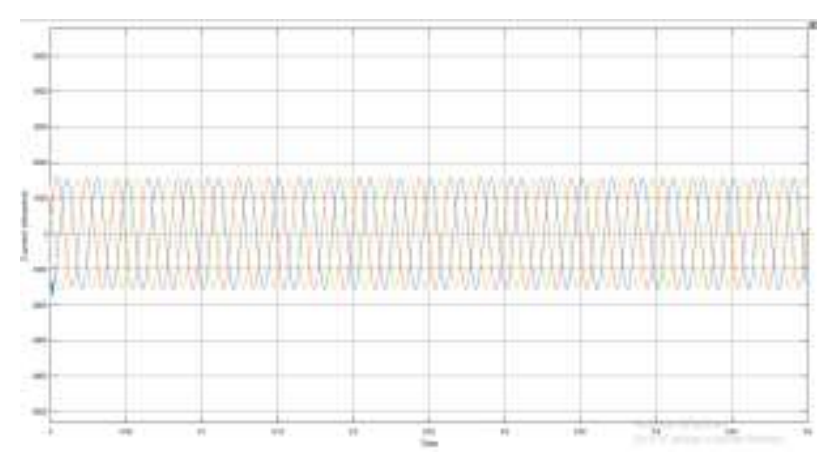

Figure 20 Current driven at the loading point in system having PQ_PI controller for compensation

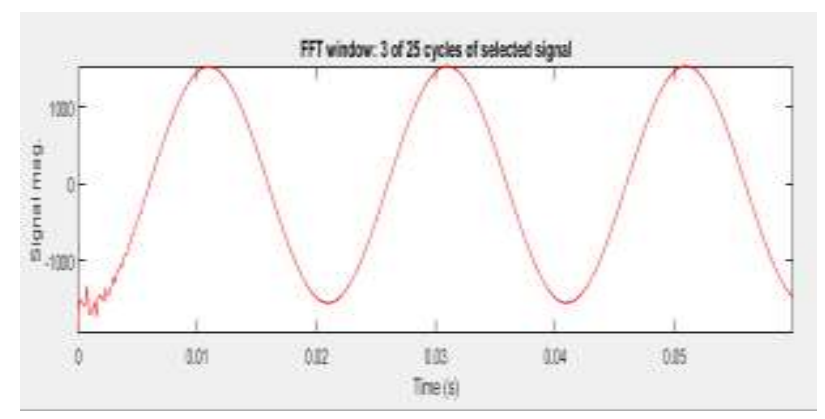

Figure 21 FFT analysis Current driven at the loading point in system having PQ_PI controller for compensation

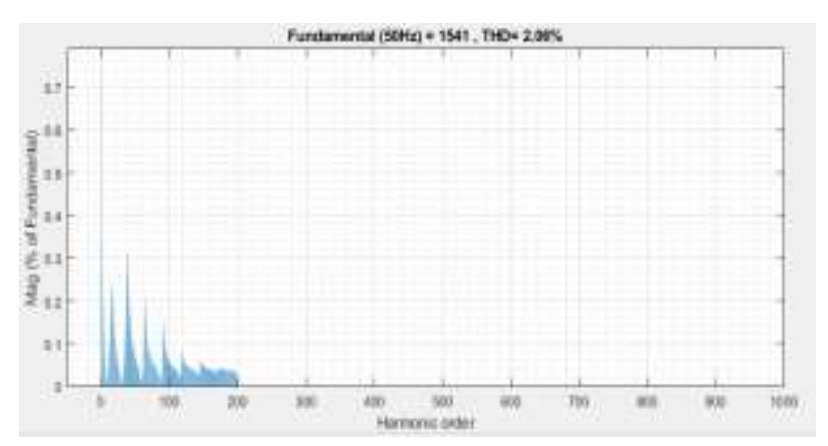

Figure $22 \mathrm{THD} \%$ in theCurrent driven at the loading point in system having PQ_PI controller for compensation

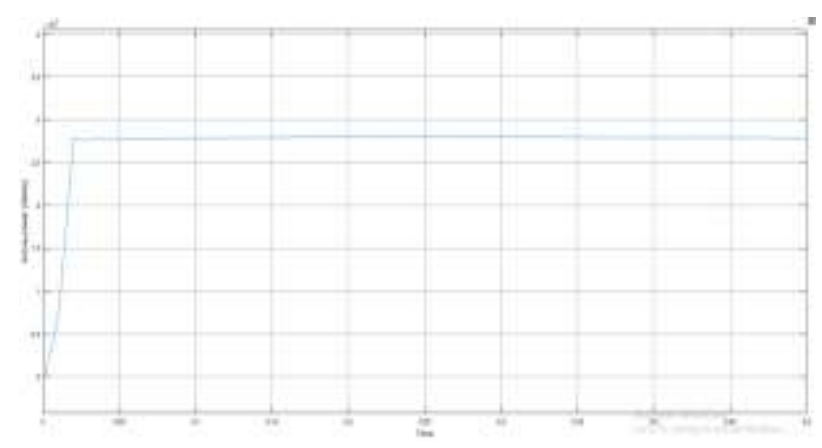

Figure 23 Active Power measured at the loading point in system having PQ_PI controller for compensation

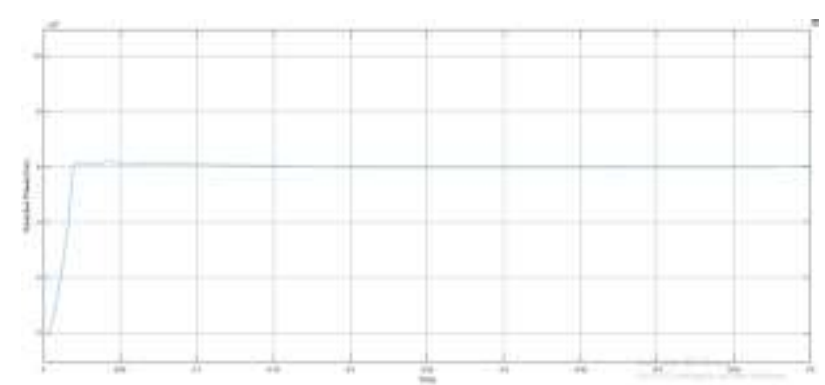

Figure 24 Reactive Power measuredin line in system having PQ_PI controller for compensation

\begin{tabular}{|c|c|c|c|}
\hline Parameters/system & $\begin{array}{c}\text { system having } \\
\text { voltage } \\
\text { regulation } \\
\text { control for } \\
\text { compensation }\end{array}$ & $\begin{array}{c}\text { System having } \\
\text { PQ_PI } \\
\text { controller for } \\
\text { compensation }\end{array}$ & $\begin{array}{c}\text { DE } \\
\text { optimization } \\
\text { controller for } \\
\text { compensation }\end{array}$ \\
\hline $\begin{array}{c}\text { Active power } \\
\text { output }\end{array}$ & $27.88 \mathrm{MW}$ & $27.89 \mathrm{MW}$ & $28.1 \mathrm{MW}$ \\
\hline Line Voltage & $20 \times 10^{4} \mathrm{~V}$ & $20 \times 10^{4} \mathrm{~V}$ & $20 \times 10^{4} \mathrm{~V}$ \\
\hline THD\% in voltage & $2.19 \%$ & $2.17 \%$ & $2.10 \%$ \\
\hline THD \% in current & $2.32 \%$ & $2.06 \%$ & $2.02 \%$ \\
\hline Reactive Power & $6.2 \mathrm{MVar}$ & $6.01 \mathrm{MVar}$ & $5.8 \mathrm{MVar}$ \\
\hline output & & & 0.91 \\
\hline Power factor in the & 0.90 & 0.90 & \\
\hline
\end{tabular}

\section{Conclusion}

The large-scale wind-solar hybrid system has a lot of prospects right now. When especially in comparison to wind and solar power alone, the large-scale wind/solar hybrid system is more reliable. Power electronics inverter can hook up DC microgrid loads in the form of active loads to the electrical power distribution system. Modeling the transients imposed on the electrical distribution network by volatile loads can be aided by making proper use of the energy stored in expansion joints. The results of the simulation revealed that a large wind/solar hybrid system with the envisaged compensator control approach is better suited to voltage transients.

\section{REFERENCES}

[1] AK. Mishra, S. R. Das, P. K. Ray, R. K. Mallick, A. Mohanty\& D. K. Mishra, "PSO-GWO Optimized Fractional Order PID Based Hybrid Shunt Active Power Filter for Power Quality Improvements"., IEEE Access, 8, 7449774512, 2020.

[2] J. Ma and X. Ma, "Distributed Control of Battery Energy Storage System in a Microgrid," 8th International Conference on Renewable Energy Research and Applications 
(ICRERA), Brasov, Romania, pp. 320-325, doi: [12] Hossain E, Tr MR, Padmanaban S, Ay S, Khan I 10.1109/ICRERA47325.2019.8996504, 2019.

(2018) "Analysis and mitigation of power quality issues in

[3] W. U. Tareen, S. Mekhilef, M. Seyedmahmoudian\&

B. Horan, "Active power filter (APF) for mitigation of power quality issues in grid integration of wind and photovoltaic energy conversion system”, Renewable and Sustainable Energy Reviews, Vol. 70, pp. 635-655, 2017.

distributed generation systems using custom power devices".

IEEE Access 6:16816-16833.

[13] MallikarjunHudedmani, ChaitanyaJambotkar "Modeling and analysis of Solar PV, Wind and Hybrid Energy System for Remote area", International Journal of [4] N. B. Kumar, K. K. Chowdary and V. Advanced Research Foundation, Volume 3, Issue 8, August Subrahmanyam, "Renewable Energy Hybrid Power System 2016.

with Improvement of Power Quality in Grid by using DVSI", Renewable Energy, Vol.6 No.09, 2019.

[5] N. R. Tummuru, M. K. Mishra, and S. Srinivas, "Multifunctional VSC controlled micro grid using instantaneous symmetrical components theory," IEEE Trans. Sustain. Energy, vol. 5, no. 1, pp. 313-322, Jan.2014.

[6] Y. Zhang, N. Gatsis, and G. Giannakos, "Robust energy management for micro grids with high-penetration renewable,” IEEE Trans. Sustain. Energy, vol. 4, no. 4, pp. 944-953, Oct. 2013.

[7] M. Schonardie, R. Coelho, R. Schweitzer, and D. Martins, "Control of the active and reactive power using dq0 transformation in a three-phase grid-connected PV system," in Proc. IEEE Int. Symp. Ind. Electron. May 2012, pp. 264269.

[8] M. Singh, V. Khadkikar, A. Chandra, and R. Varma, "Grid interconnection of renewable energy sources at the distribution level with power-quality improvement features," IEEE Trans. Power Del., vol. 26, no. 1, pp. 307-315, Jan. 2011.

[9] P. Rodriguez et al., "A stationary reference frame grid synchronization system for three-phase grid-connected power converters under adverse grid conditions," IEEE Trans. Power Electron., vol. 27, no. 1, pp. 99-112, Jan. 2012. [10] Manivannan A, Murali.G,"Analysis of Power Quality Problems in Solar Power Distribution System" IEEE Trans., vol.2, no. 3, May-June2013.

[11] Devassy S, Singh B (2018) Design and performance analysis of three-phase solar PV integrated upqc. IEEE Trans IndAppl 54(1):73-81. 